\title{
Erratum to: ABATE: A New Tool to Produce Marginal Abatement Cost Curves
}

\author{
Oswald Marinoni $^{1} \cdot$ Martijn van Grieken $^{1,2}$
}

\section{Erratum to: Comput Econ (2016) 48:367-377 DOI: 10.1007/s10614-015-9524-5}

Unfortunately, in the first page of the original publication, software availability link to download the tool that is described in the paper is not included. The link is provided in this erratum.

Software availability ABATE is available for download from http://doi.org/10.4225/ 08/578DA7F5877FB.

The online version of the original article can be found under https://doi.org/10.1007/s10614-015-9524-5.

Oswald Marinoni oswald.marinoni@csiro.au

1 CSIRO Land and Water, Water for a Healthy Country Flagship, GPO Box 2583, Brisbane, QLD 4001, Australia

2 Gimix BV, Raoul Hynckestraat 10, 5645 LE Eindoven, The Netherlands 